\title{
O Orçamento Participativo e a democratização da gestão pública municipal - a experiência de Vitória da Conquista (BA)
}

\author{
Flávio Santos Novaes \\ Universidade Federal da Bahia (Ufba) \\ Maria Elisabete Pereira dos Santos \\ Universidade Federal da Bahia (Ufba)
}

\begin{abstract}
Este artigo discute as possibilidades do Orçamento Participativo (OP) de ampliar a democratização da gestão pública e de interferir efetivamente na destinação de recursos municipais. Parte-se da teoria da democracia participativa e do histórico do OP no Brasil para analisar a experiência de Vitória da Conquista (BA). Recorrendo a pesquisa documental, entrevistas, observação direta e aplicação de questionários a delegados do IX Congresso do OP de Vitória da Conquista (2011), o trabalho conclui que essa experiência contribuiu parcialmente com a democratização da gestão municipal, uma vez que não consistiu em fórum de efetiva participação da população na definição de políticas públicas e na aplicação de recursos municipais.
\end{abstract}

Palavras-chave: orçamento participativo; democracia participativa; gestão municipal.

Presupuesto Participativo y la democratización de la gestión pública municipal — la experiencia de Vitória da Conquista, Brasil

Este artículo analiza las posibilidades del Presupuesto Participativo (OP) para ampliar la democratización de la gestión pública y de intervenir con eficacia en la asignación de los recursos municipales. Se inicia con la teoría de la democracia participativa y la historia del OP en Brasil para analizar la experiencia de Vitória da Conquista, Bahia. Usando la investigación documental, entrevistas, observación directa y cuestionarios a delegados del IX Congreso del OP de Vitoria da Conquista (2011), el artículo concluye que esta experiencia contribuye parcialmente a la democratización de la gestión municipal, ya que no es foro para discutir la participación efectiva de los ciudadanos en la formulación de políticas y la aplicación de los recursos públicos municipales.

Palabras clave: presupuesto participativo; democracia participativa; gestión municipal.

DOI: http://dx.doi.org/10.1590/0034-76121668

Artigo recebido em 31 jul. 2013 e aceito em 25 abr. 2014. 
The Participatory Budget and the democratization of the municipal public management - the experience of Vitória da Conquista, Brazil

This article discusses the possibilities of the Participatory Budget (PB) to expand the democratization of the public management and to effectively intervene in the allocation of municipal resources. It starts from the theory of the participatory democracy and the from PB's history in Brazil to analyze the experience of Vitória da Conquista, Bahia. Using documentary research, interviews, direct observation and questionnaires to the delegates of the IX Congress of Vitória da Conquista PB (2011), we conclude in this article that this experience partially contributed to the democratization of the municipal management, since it was not considered a forum of effective participation of the population in the definition of public policies and in the application of municipal resources.

KEYWORDs: participatory budget; participatory democracy; municipal management.

\section{Introdução}

Com a redemocratização da sociedade brasileira, a partir dos anos 1980, novos espaços de participação da sociedade civil foram criados na tentativa de romper com os limites de um Estado com resquícios autoritários, centralizadores, clientelistas e patrimonialistas. O novo arcabouço constitucional criado em 1988 estabeleceu mecanismos institucionais de participação, abrindo à sociedade diferentes possibilidades de atuação no aparato estatal. Surgiram assim experiências consideradas inovadoras por incorporarem a participação do cidadão na definição de políticas públicas e em decisões no âmbito da gestão local, a exemplo dos conselhos gestores, das conferências de políticas, dos orçamentos participativos e de outros fóruns. Essa inovação institucional e organizacional despertou o interesse de pesquisadores, gestores e cidadãos sobre sua dinâmica e sobre seus resultados para a gestão pública e para a vida da população, e tem levado ao questionamento se essas instituições têm efetivamente sido capazes de alterar e de democratizar a gestão da res publica.

$\mathrm{Na}$ busca dessa compreensão, este artigo tem como objetivo discutir se o Orçamento Participativo contribui para a democratização da gestão pública municipal e da distribuição dos seus recursos orçamentários, tomando como caso de estudo a experiência de Vitória da Conquista-BA. Fundamentam essa reflexão teóricos da democracia como Boaventura Santos (2009a), Coelho e Nobre (2004), Dahl (1981, 2006), Held (2007), Pateman (1970), Santos e Avritzer (2009) e Sartori (1994). O trabalho realiza uma caracterização do orçamento participativo no Brasil discutindo seus principais avanços e limites e apresenta a experiência do Orçamento Participativo de Vitória da Conquista (BA) (OP-VC), que é analisado em seu percurso, suas características e desafios, sendo o mesmo confrontado com os desafios suscitados por questões relativas à democratização da gestão pública e da aplicação de seus recursos orçamentários.

A escolha do OP-VC se justifica pelo seu pioneirismo na Bahia e no Nordeste brasileiro, além do fato de desenvolver-se ininterruptamente ao longo de 16 anos (de 1997 a 2012) em meio a sucessivas gestões municipais com mesmo projeto político. Essas características diferenciam essa experiência de outras observadas no Brasil, despertam o interesse de pes- 
quisadores e gestores públicos, permitem analisar o aprofundamento de experiências locais participativas e a consolidação de algumas de suas práticas.

Essa discussão se situa em um contexto político bastante distinto daquele que deu origem ao orçamento participativo na década de 1980. Apesar da atualidade da proposta de implementação de mecanismos de participação e controle democrático da gestão pública, as forças políticas que introduziram o OP como opção contra-hegemônica estão, hoje, na condição de governo, minimizando o caráter contestatório anteriormente existente. Além disso, o processo de disseminação dessa ferramenta de gestão representa uma apropriação do instrumento, com o enfraquecimento do seu papel de catalisador da participação popular, e perda do acentuado caráter ideológico e partidário inicialmente verificado.

É nesse cenário que a referida experiência se converte em um estudo de caso único (Yin, 2005), sendo utilizada uma abordagem qualitativa que envolve técnicas como análise de documentos, pesquisa bibliográfica, entrevistas, observação direta e questionários (Cooper e Schindler, 2003:132). As entrevistas utilizadas nesta pesquisa foram do tipo "abertas", "semiestruturadas" (presenciais e gravadas em áudio) e também “estruturadas" (escritas), encaminhadas e respondidas por meio de correio eletrônico. O uso de diferentes estratégias requereu, para a análise dos dados obtidos, a utilização do recurso da "triangulação de dados" (Flick, 2009).

Ao longo do trabalho de campo, foram entrevistados integrantes e ex-integrante da equipe do Orçamento Participativo de Vitória da Conquista, secretários municipais ligados ao processo de idealização e implantação do OP-VC, secretários municipais com vinculação funcional ao orçamento participativo, integrantes de movimentos sociais que acompanham e estudam o processo do OP-VC, vereadores da oposição e militantes sindicais das categorias dos servidores municipais, em especial dos professores e dos servidores da saúde, que estão dentre as mais numerosas.

As entrevistas foram complementadas com o recurso da observação direta e de questionários, aplicados a 350 delegados do IX Congresso do OP-VC (2011), escolhidos de modo não probabilístico, como amostra por conveniência ou acidental (Barros e Lehfeld, 1990), dentre os seus 530 delegados eleitos, dos quais 263 questionários foram respondidos e devolvidos ao pesquisador (75\%) e 262 foram considerados válidos, buscando identificar o perfil socioeconômico dos delegados, suas percepções sobre o processo participativo e sobre os seus resultados. Para a análise desses dados recorreu-se ao software Sphinx Léxica $囚$.

Além das entrevistas e dos questionários, foram consultados documentos oficiais do OPVC, como atas de congressos e plenárias regionais, ofícios, históricos do OP-VC, jornais, boletins, regimentos internos, relatórios com propostas de grupos temáticos, relações de obras em andamento, relações de demandas aprovadas e demandas atendidas. Por meio da pesquisa bibliográfica sobre o caso estudado, foram consultadas e analisadas dissertações de mestrado que avaliaram o OP-VC, como Andrade (2005) e Rocha (2008), além de outros estudos que também abordaram a experiência de Vitória da Conquista (BA), a exemplo de Milani (2007), Mota (2007), Pinho (2006) e Pires e Tomas (2007). 
O presente artigo se estrutura da seguinte forma: a seção 2 apresenta uma reflexão sobre a teoria da democracia participativa e o orçamento participativo; a seção 3 caracteriza o orçamento participativo no Brasil, avaliando seus avanços e limites; por sua vez, a seção 4 analisa o percurso do Orçamento Participativo de Vitória da Conquista (BA) (OP-VC), discutindo características, limitações e desafios ao longo de sua existência, cotejando as possibilidades de democratização da gestão municipal e do seu orçamento, para então chegarmos às considerações finais.

\section{Orçamento Participativo e democracia participativa}

Alguns autores no campo da teoria democrática enfatizam os temas da participação e da deliberação como o centro de um grande debate sobre a renovação da democracia (Avritzer, 2009b; Coelho e Nobre, 2004; Held, 2007; Santos, 2009a). Desse modo, a recente experiência de democratização do Brasil passa a se constituir em uma referência, dada a criação de canais de participação e deliberação com a redemocratização a partir dos anos 1980, a exemplo do orçamento participativo, dos conselhos gestores de políticas públicas, dos mecanismos de deliberação no interior das agências de regulação, das conferências, da legislação participativa e das audiências públicas. Esses mecanismos assumem maior importância se comparados com a suposta perda de vitalidade da democracia nos países capitalistas do Norte (Coelho e Nobre, 2004).

Held (2007) destaca que a relativa "tranquilidade" em torno da institucionalização de instrumentos democráticos nos anos 1990 deu lugar a pressões internas e externas e abriu espaços para se repensar a capacidade de essa forma de gestão viabilizar a participação dos cidadãos e o desenvolvimento social, além de se contrapor à apatia que toma conta do cidadão nos tempos atuais. Para o autor, o conceito clássico de democracia se encontra associado à participação política; ele acrescenta ainda que, diante dos questionamentos à democracia como forma de governo em que o povo governa, muito provavelmente o seu significado permaneça instável, passível de dúvidas e controvérsias.

Tendo como objeto central da sua análise as variantes de democracia, Held (2007) apresenta dois tipos gerais e que se opõem - a democracia direta ou participativa e a democracia liberal ou representativa - para, em seguida, discutir alguns modelos clássicos e os modelos recentes de democracia. Estes últimos seriam o elitismo competitivo, o pluralismo, a democracia legal, a democracia deliberativa e a democracia participativa. Todavia, interessa aqui abordar apenas esta última.

Em verdade, o conceito de democracia participativa tem múltiplas fontes de inspiração, a exemplo de Rousseau, da tradição anarquista, das posturas marxistas libertárias e dos pluralistas (Held, 2007). O referido conceito pode ser considerado "un nuevo modelo de democracia emergente", tendo sido aprofundado por autores da chamada Nova Esquerda, como Carole Pateman e C. B. Macpherson, por volta dos anos 1960 (Held, 2007:300). 
Como afirma Carole Pateman (1970), o termo "participação" tornou-se popular no vocabulário político durante os anos 1960, impulsionado pelas insatisfações e reivindicações de vários segmentos sociais. Desde então, o termo se refere a uma variedade de situações, circunstâncias e realidades sociais. A convicção dos "teóricos clássicos" da democracia na ideia da ampla participação do conjunto das pessoas deveria ser revisada, segundo Pateman (1970), uma vez que nas abordagens ortodoxas o conceito de participação tem um papel bem reduzido e seria até maior a preocupação com a estabilidade do sistema político do que propriamente com uma larga participação.

Para a autora, mesmo as teorias sobre democracia formuladas no século XX, como a de Joseph Schumpeter, que criticava aspectos da doutrina clássica e teve grande influência na teoria política moderna, não enfatizavam o papel central da participação, uma vez que, para Schumpeter, "(...) his revised theory it is the competition by potential decision makers for the people's vote that is the vital feature" (Pateman, 1970:4). Esse conceito de democracia se caracteriza pela competição das elites por liderança e essa competição política por votos se compara à disputa de mercado, assemelha eleitores a consumidores. Teóricos da contemporânea teoria da democracia, como Berelson, Dahl, Sartori e Eckstein, também não teriam, na opinião de Pateman (1970), explorado o papel da participação na sociedade democrática. Dahl, por exemplo, apresenta argumentos sobre os possíveis riscos de um aumento da participação das pessoas comuns (Pateman, 1970:10).

Onde estariam, então, as raízes de uma teoria da participação? Segundo Pateman (1970:20), nas teorias de J. S. Mill e J. J. Rousseau, para as quais "(...) participation has far wider functions and is central to the establishment and maintenance of a democratic polity (...)". Assim, a autora destaca entre os teóricos da participatory democracy J. S. Mill e Rousseau, este último reconhecido como um dos fundadores do debate sobre a democracia participativa. Há ainda destaque para a contribuição de G. D. H. Cole.

Boaventura Santos (2009a) insere as discussões em torno da democracia participativa no contexto da chamada "globalização neoliberal", no qual estariam em confronto duas concepções (similares aos dois "tipos gerais" de Held, 2007): o modelo hegemônico de democracia (democracia liberal, representativa) e a democracia participativa ou "democracia popular". Esta última teria assumido uma nova dinâmica “(...) protagonizada por comunidades e grupos sociais subalternos em luta contra a exclusão social e a trivialização da cidadania, mobilizados pela aspiração de contratos sociais mais inclusivos e de democracia de mais alta intensidade" (Santos, 2009a:32).

Santos e Avritzer (2009) sugerem o estreitamento dos vínculos entre democracia participativa e democracia representativa e propõem uma solução diferente daquela da "teoria hegemônica", apontando duas formas de arranjo que seriam uma resposta alternativa ao problema democrático: a combinação entre democracia representativa e democracia participativa por meio de expedientes como a coexistência e a complementaridade.

É preciso ressaltar que, dentre os teóricos da democracia, existem posições menos otimistas em relação às possibilidades da democracia participativa. Robert Dahl (1981), por exemplo, quando contrasta hegemonias e poliarquias, considera que estas ampliam as 
possibilidades de participação e dão maior autonomia aos indivíduos e grupos em relação ao governo; mesmo assim, aponta crescente desinteresse pela participação em sociedades modernas e democráticas. Algumas explicações para esse desinteresse seriam a reduzida recompensa atribuída à participação, a descrença quanto às possibilidades de a participação alterar os resultados da vida política, a crença do indivíduo na limitação dos seus conhecimentos, que reduziria a eficácia da sua ação, ou mesmo os obstáculos colocados à participação na vida política.

Dahl (2006) analisa as propostas do Students for a Democratic Society, de 1962, por mudanças pacíficas em direção a uma sociedade mais justa e mais democrática, considerando uma solução de democracia participativa que encontrava forte oposição no sistema político norte-americano, além de obstáculos como o tempo requerido para a participação e os limites viáveis para uma ampla participação. Suas reflexões apontam a possibilidade de aumento da desigualdade política e da irrelevância da democracia, sendo a esperança de igualdade política plena vista como fora do alcance, embora Dahl (2006) acredite que a cultura dominante do consumismo competitivo, incapaz de gerar felicidade, possa levar mais norte-americanos a descobrirem que a qualidade de suas vidas poderia ser melhorada por meio da ação cívica, de uma cidadania ativa e empenhada.

Também cético em relação à democracia participativa, Sartori (1994) a associa às noções próximas "e mais claras" de democracia direta, democracia de referendo, democracia eleitoral e democracia representativa, das quais a democracia participativa tanto se aproxima quanto se afasta. $\mathrm{O}$ autor chega a negar a democracia participativa como uma novidade ou mesmo como uma teoria por si só, pois entende que o status de teoria e sua novidade dependem da centralidade atribuída ao conceito de participação.

Se a participação for compreendida como envolvimento pessoal e ativo, como essência das "microdemocracias", de pequenos grupos, segundo Sartori (1994), a democracia participativa se aproxima perigosamente do terreno do chamado elitismo, que ela tanto critica. Por isso, sua opinião é que "(...) o tomar parte é significativo, autêntico e real apenas no âmbito de pequenos grupos" (Sartori, 1994:160) e que isso levaria a democracia participativa apenas a enfatizar e a dar importância a "grupos pequenos e intensos", o que é um dos significados do "elitismo".

De todo modo, essa discussão em torno dos modelos de democracia pode ser relacionada com as discussões em torno do orçamento participativo, sendo possível entender esses experimentos não apenas como característicos de um determinado modelo ou tipo de democracia, mas como uma experiência que transita entre diferentes modelos e talvez seja essa a sua relevância e novidade, a razão da sua vitalidade e do interesse que desperta.

O orçamento participativo é um tema que ganhou relevância nas últimas décadas, especialmente após a experiência iniciada na cidade de Porto Alegre, em 1989, que foi amplamente estudada e ainda desperta interesse nacional e internacional de acadêmicos e de gestores públicos. Outro exemplo considerado bem-sucedido é o OP de Belo Horizonte, que também tem sido muito pesquisado, sendo ambos amplamente discutidos em estudos realizados por Boaventura Santos (2009a, 2009b), Avritzer (2003, 2009a, 2009b), Avritzer e 
Navarro (2003), Fedozzi (1997), Genro e Souza (1997), Marquetti (2003), Wampler (2003), dentre outros.

Outras experiências de OP não tiveram a mesma repercussão e sucesso das de Porto Alegre e Belo Horizonte, a exemplo dos casos de São Paulo, Salvador e Recife, como se verá. Essa constatação desperta o interesse em pesquisar outras experiências de OP, como a de Vitória da Conquista (BA), na tentativa de identificar suas características e avaliar esse instrumento de controle social da população sobre o poder público municipal, em especial o Executivo, discutindo particularmente se o OP democratiza a sua gestão e se pode contribuir para uma melhor distribuição dos recursos públicos para toda a população.

Autores como Wampler (2003), por exemplo, discutem a relação entre democracia participativa, distribuição dos recursos orçamentários e eficiência da administração pública, definindo critérios a serem utilizados na avaliação dos resultados do OP em três áreas específicas: a democracia, a racionalização da administração local e a justiça redistributiva. Na concepção do autor, o OP representa um processo de construção de políticas que modifica as práticas anteriores de planejamento e de elaboração orçamentária no Brasil e é um meio de aprovar políticas públicas com potencial para tornar mais eficiente o uso dos recursos escassos, devido ao monitoramento dos gastos e obras pelos cidadãos.

Por sua vez, Kliksberg (2007) situa o OP em meio a um processo de ampliação da participação na América Latina e também de crescimento da pressão da cidadania da região por mais participação. Alertando sobre os obstáculos à participação, o autor assinala a existência do risco de frustrações com algumas promessas participativas que depois se revelam práticas clientelistas ou manipulativas, além de questionar se o impulso participativo observado no início do século XXI não seria apenas mais uma "moda" ou se representa condições favoráveis para uma sólida participação no contexto histórico latino-americano.

Pesquisando experiências de participação social na América Latina e na Europa, Milani (2008) ressalta o caráter de inovação das experiências latino-americanas, inclusive servindo de modelo aos países do Norte para se pensar a democracia e suas possíveis reformas. O pressuposto do autor é de que a participação social tornou-se, já nos anos 1990, um dos princípios organizativos dos processos de elaboração das políticas públicas e de deliberação democrática em nível local.

O contexto da América Latina, segundo Kliksberg (2007), é de aprofundamento dos processos de democratização, observando-se sociedades civis mais ativas e articuladas (o que favorece o surgimento de práticas da democracia participativa), inclusive ampliando o número das denominadas Organizações da Sociedade Civil (OSC). O autor aponta também as boas taxas de crescimento econômico observadas na região, no período de 2004 a 2006, embora os avanços políticos e econômicos e a existência de um excepcional potencial de recursos naturais ainda convivam com agudos problemas sociais, como a pobreza e a pobreza extrema.

Assim, num contexto de "pobreza persistente" (Kliksberg, 2007:542), com destaque negativo para o Brasil, é possível falar numa dinâmica na América Latina em que os agudos níveis de desigualdade favorecem a reprodução contínua dessa mesma desigualdade, impedindo a redução da pobreza mesmo em conjuntura de crescimento econômico. Esse paradoxo 
leva o autor a questionar o papel da participação "en la región más desigual del planeta" (Kliksberg, 2007:542). ${ }^{1}$ Milani (2008) também indaga quem participa dos instrumentos participativos criados na América Latina e quais desigualdades subsistem no processo de participação, a exemplo das diferenças entre a participação de homens e mulheres ou das desigualdades quanto à participação de associações mais consolidadas ao lado de outras menos estruturadas.

Tem-se, aqui, um importante questionamento sobre as possibilidades da democracia participativa diante do problema da desigualdade social. Uma solução proposta por Kliksberg (2007) estaria na busca de um grande acordo ("gran concertacción"), envolvendo o Estado, as empresas e a sociedade civil, na tentativa de ampliar a equidade na América Latina, podendo ser a participação um grande dinamizador dessas políticas e acordos. Afirmando a viabilidade da participação na América Latina, Kliksberg (2007) aponta a existência de experiências significativas de participação em quase todos os países da região e analisa três exemplos que considera exitosos: o Orçamento Participativo de Porto Alegre, a Villa El Salvador (Peru) e a cidade de Rosário (Argentina). Vale frisar que estes dois últimos exemplos também incorporaram entre suas práticas democráticas o "pressupuesto participativo", influenciados pela experiência porto-alegrense.

A discussão sobre a democracia participativa como meio de aprofundar os processos democráticos existentes e de enfrentar as desigualdades sociais e as demandas de maior envolvimento da sociedade civil na definição dos rumos da gestão pública passa pela compreensão da dinâmica de fóruns criados nas últimas décadas, como o OP e outras instituições participativas. Vejamos a seguir como o orçamento participativo se desenvolveu no Brasil e suas possibilidades de ampliar a democracia.

\section{O Orçamento Participativo no Brasil}

Experiências de participação popular na gestão local, incluindo o orçamento público, são conhecidas desde a década de 1970, com destaque para os casos de Lajes (SC) e Boa Esperança (ES), entre 1978-82, seguidos de outros como Vila Velha (ES), Diadema (SP), Piracicaba (SP) (Bossois, 1987; Pires, 2000, 2001). Segundo Pires (2000), na fase de 1989-92 surgiram as experiências participativas lideradas pelo Partido dos Trabalhadores (PT), que tinham duas características essenciais: tornar o orçamento municipal um catalisador da participação popular e ter um acentuado caráter político-ideológico. São dessa fase os casos de Porto Alegre (RS), Santo André e Santos (SP), Ipatinga e Betim (MG) e outros.

O orçamento participativo no Brasil tem sido estudado por autores como Avritzer (2003, 2009a, 2009b), Fedozzi (1997), Genro e Souza (1997), Navarro (2003), Pires (2000, 2001), Ruiz Sanchéz (2002) e Wampler (2003). Um estudo de relativa repercussão foi realizado por Santos (2009b), juntamente com Avritzer (2009a), que estudaram o OP de Porto Alegre, o

\footnotetext{
${ }^{1}$ Essa afirmação pode ser relativizada quando se pensa na África, em especial na África subsaariana.
} 
de maior projeção nacional e internacional, e o compararam com diferentes experiências de democracia participativa no Hemisfério Sul (Moçambique, Colômbia, África do Sul, Índia) e em Portugal.

Avritzer (2009a) afirma que a reivindicação dos conselhos populares de participação no orçamento de Porto Alegre remonta a 1986, ainda na gestão do Partido Democrático Trabalhista (PDT). Todavia, a criação de uma instância participativa de deliberação sobre o orçamento somente teve início na gestão seguinte, liderada pelo Partido dos Trabalhadores (PT), em resposta à ação de múltiplos atores, aliada à existência de um forte movimento comunitário na cidade e à recuperação da ideia de cidadania pela sociedade civil brasileira.

No caso de Belo Horizonte (MG), o OP teve início em 1993, quando o PT liderava a Frente BH Popular, e tinha entre suas propostas de gestão o envolvimento efetivo da população nas decisões sobre os investimentos dos recursos públicos. Embora a nova gestão tivesse herdado uma situação financeira difícil e contasse com poucos recursos para investimentos, foi possível realizar mobilizações e envolver a população para discutir sobre obras e outros empreendimentos a serem realizados no ano seguinte (Gomes, 2005). Com o OP em Belo Horizonte foram criados critérios como a distribuição de recursos de forma diretamente proporcional à população e inversamente proporcional à renda, descentralizando as políticas de urbanização da cidade, numa tentativa de alcançar a chamada "inversão de prioridades", canalizando recursos para as regiões mais carentes e populosas. Uma inovação do município foi a criação do Orçamento Participativo da Habitação, em 1996, responsável por parte de sua política habitacional.

Para Santos (2009b:457-458), o OP de Porto Alegre foi “(...) uma iniciativa urbana orientada para a redistribuição dos recursos da cidade a favor dos grupos sociais mais vulneráveis, usando os meios da democracia participativa", uma inovação institucional que tinha como vetores a eficácia administrativa, a responsabilidade e a qualidade da participação, a autonomia. Em sua análise, o OP de Porto Alegre seria uma forma de gestão pública capaz de romper com a tradição autoritária e patrimonialista das políticas públicas, por meio da participação direta da população em diferentes fases, desde a preparação até a implementação orçamentária, definindo prioridades para investimentos.

O OP de Porto Alegre funciona com base nas assembleias plenárias regionais e temáticas, nos fóruns de delegados e no Conselho do OP. São realizadas duas "rodadas" de assembleias plenárias em cada uma das 16 regiões e em cada uma das seis áreas temáticas. A regionalização é uma característica do OP de Porto Alegre e funciona “(...) de acordo com critérios socioespaciais e com a tradição de organização comunitária da cidade” (Santos, 2009b:471). Para Santos (2009b), o Conselho do Orçamento Participativo (COP) é a principal instituição participativa, uma oportunidade de os cidadãos eleitos tomarem conhecimento das finanças municipais, na qual se discutem e definem critérios gerais para a distribuição dos recursos, além de fórum em que são defendidas as prioridades das regiões e dos temas.

Analisando as experiências de Belo Horizonte e de Porto Alegre, Avritzer (2009a:576) define o OP como "(...) uma política participativa em nível local que responde a demandas dos setores desfavorecidos por uma distribuição mais justa dos bens públicos nas cidades brasilei- 
ras", composto por uma etapa de participação direta dos interessados e outra etapa em que tal participação se dá por meio do conselho de delegados. Na cidade de Porto Alegre ocorre uma primeira rodada de assembleias regionais e temáticas, seguida de uma rodada intermediária de tais assembleias, e um terceiro momento, que é a segunda rodada de assembleias (Fedozzi, 1997). Já em Belo Horizonte são realizadas duas rodadas de assembleias regionais e um fórum de prioridades regionais (no qual o formato final do orçamento é definido). Neste último são eleitos os delegados que monitorarão as obras aprovadas por meio da Comforça (Comissão de Fiscalização do OP). Existe ainda um processo interno de debate, representado pelas "Caravanas de Prioridades", que é um processo de negociação entre membros de cada uma das comunidades ou sub-regiões do OP, com a visita de delegados eleitos às propostas de obras apresentadas para definir quais serão aprovadas.

Uma característica comum aos processos de OP de Belo Horizonte e de Porto Alegre é a existência das assembleias regionais, uma prática comum aos movimentos comunitários, como outras que resultaram das mobilizações populares dos anos de 1970 e 1980, que buscavam a ampliação da participação e o estabelecimento de critérios de justiça no processo de deliberação para aumentar a sua credibilidade.

Ao contrário das experiências participativas de Belo Horizonte e de Porto Alegre, consideradas por muitos autores exemplos de OP bem-sucedidos, ainda que por determinado período, outros casos de orçamento participativo não apresentaram tanto sucesso. Em Recife, nas gestões municipais dos períodos de 1993-96 e 1997-2000, ocorreu um exemplo malsucedido de OP, cujas razões estariam na falta de empenho por parte da administração municipal em fortalecer o mecanismo participativo, na tentativa de incorporação pela sociedade política de lideranças do movimento comunitário (Avritzer, 2003; Coêlho, 2007). O estudo de Fernandes (2004) revela que Jarbas Vasconcelos (do Partido do Movimento Democrático Brasileiro - PMDB), aliado ao Partido da Social Democracia Brasileira (PSDB), foi eleito prefeito do Recife, em 1992, com proposta de democratização da gestão municipal, estimulando a organização dos conselhos setoriais previstos na Constituição Federal e na Lei Orgânica Municipal, desenvolvendo o Programa Prefeitura nos Bairros, do qual surgiu a ideia de realizar o orçamento participativo, que não foi implementado em sua gestão, sendo apenas estabelecido o plano de investimento regionalizado (1996).

A gestão seguinte, 1997-2000, comandada pelo Partido da Frente Liberal (PFL), com o apoio de Jarbas Vasconcelos (PMDB), implantou o OP, embora contasse com a resistência da Câmara dos Vereadores, que aprovou uma indicação para a sua extinção, gerando uma crise política na gestão municipal, solucionada com a permissão para que os vereadores pudessem incluir seus projetos no OP (Fernandes, 2004:198-199). Porém, a razão do insucesso do OP recifense também poderia ser buscada na incapacidade do seu "desenho institucional" em transferir elementos deliberativos para as próprias comunidades ou associações, aliada ao reduzido nível de execução orçamentária de obras aprovadas pelo OP (Avritzer, 2003; Coêlho, 2007).

Por sua vez, na experiência verificada em Salvador, na gestão de 1993-96, não teria existido interesse político em descentralizar o processo decisório, houve problemas de articu- 
lação entre planejamento e orçamento, além de uma limitação de recursos para investimentos, o que resultou em insucesso (Boschi, 1999; Fernandes, 2004). A gestão municipal do período 1993-96 era comandada por Lídice da Mata, do PSDB, que liderava uma coligação de nove partidos de esquerda e centro-esquerda (Fernandes, 2004:177), e derrotara o candidato do PFL, apoiado pelo governador Antônio Carlos Magalhães, liderança autoritária do Estado e expoente do chamado "Carlismo".

Além das dificuldades que a prefeita enfrentou com o elevado endividamento da prefeitura, havia divergências internas em seu partido e cerco político à sua gestão, patrocinado pelo referido governador, por meio do boicote da mídia controlada por sua família e da realização de obras na cidade pelo governo estadual, “(...) provocando uma competição entre esferas de governo pela gestão urbana do município" (Fernandes, 2004:181). Por fim, a implantação do OP em Salvador não era um compromisso partidário (PSDB), tampouco resultado de uma política corrente de participação (ao contrário de Belo Horizonte e Porto Alegre), mas apenas uma tentativa de "sintonizar" a gestão local com as tendências modernizadoras então vigentes no país, mais do que uma opção efetiva de incluir a participação social na gestão. "Nesse sentido, a tentativa de implantar o orçamento participativo em Salvador não foi bem-sucedida e não teve qualquer repercussão institucional capaz de pressionar a gestão municipal subsequente a manter tal política" (Fernandes, 2004:187).

Outra tentativa de pouco sucesso na implantação do OP ocorreu na cidade de São Paulo (SP). Na primeira gestão do PT (1989-92), embora constasse da plataforma de campanha o "governo com auxílio dos conselhos populares", o OP não foi implantado "(...) devido à forte setorização e compartimentalização da ação de governo e à fragmentação dos movimentos sociais de forte cunho setorial nas áreas de saúde e habitação" (Ruiz Sánchez, 2002:22). Para Avritzer (2009b), na segunda gestão do PT (2001-04), a prefeita Marta Suplicy optou por transferir as políticas participativas para lideranças minoritárias à esquerda da coalizão governante, o que resultou na pouca efetividade das deliberações tomadas pelos mecanismos participativos, inclusive o OP, que foi implantado por ter sido uma promessa de campanha.

Embora a gestão de Marta Suplicy tenha criado o OP, fortalecido os conselhos existentes, como o de saúde, e criado novos conselhos, Avritzer (2009b) aponta uma limitação em sua política participativa: a busca de apoio junto a outros partidos políticos mediante a concessão de subprefeituras em troca de sustentação na Câmara de Vereadores, o que teria enfraquecido os mecanismos participativos, especialmente o OP, que não era apoiado por muitas das subprefeituras. Como resultado, o OP de São Paulo não foi capaz de promover uma distribuição de bens públicos na mesma dimensão que outras cidades, como Porto Alegre e Belo Horizonte, além de ser incapaz de disseminar o processo por todas as regiões da cidade.

Outros autores apresentam uma visão mais cética do referido processo no município de São Paulo. Bello (2007), por exemplo, considera o OP-SP "uma invenção de limitado alcance", desde o seu formato baseado em assembleias territoriais (dada a fraca organização territorial em São Paulo); a incerteza quanto às possibilidades de o OP efetivamente atender às reivindicações das populações mais carentes; e os valores relativamente pequenos do orçamento total de 2002 e 2003 destinados ao OP-SP, em comparação com o OP de Porto Alegre (de 5\% a 
$6,2 \%$, contra $9 \%$ a 15\%, respectivamente). O autor não considera, todavia, a maior complexidade política e logística e o volume de recursos orçamentários per capita do município de São Paulo, o que não faz essa experiência muito distante do OP de Porto Alegre.

Bello (2007) aponta ainda o risco de "gravitação ideológica e/ou político-partidária" da população organizada em torno do PT e da Prefeitura, isto é, a presença majoritária de militantes partidários e de integrantes da administração municipal nos fóruns promovidos pelo OP, o que poderia resultar em posturas de subordinação. Além disso, estende sua crítica também ao OP de Porto Alegre, embora reconheça sua maior credibilidade quanto à cessão de parte do poder pela prefeitura, que delegou à participação popular a eleição das prioridades de investimento (o que não ocorria em São Paulo).

A literatura sobre a democracia participativa registra outras limitações do processo de orçamento participativo. Navarro (2003:122) aponta o que considera uma debilidade do OP, o “(...) localismo paroquial do chamado 'OP demandista”, que seria uma priorização do processo ao atendimento de demandas imediatas e isoladas de cada comunidade ou bairro, impedindo a utilização do espaço participativo para a discussão de questões mais gerais da cidade ou mesmo de políticas públicas mais amplas nas áreas da saúde, educação e transporte público, por exemplo. Esse aspecto foi, inclusive, observado no OP de Vitória da Conquista (BA), como se verá.

Numa tentativa de remediar essa debilidade, Navarro (2003) defende a proposta de tornar o processo de OP "efetivamente autônomo", institucionalizado e isento do controle partidário e governamental, o que parece irreal, haja vista que a maioria das experiências de OP observadas (inclusive o OP-VC) tem surgido da decisão ou empenho dos governantes, especialmente do chefe do Executivo. No caso de Vitória da Conquista, que pode não ser muito diferente de outros municípios que implantaram o OP, a presente pesquisa constata que a implantação e a sobrevivência do orçamento participativo deve-se à ação da Prefeitura Municipal, por meio da Coordenação de OP, responsável por atividades de mobilização, divulgação e pela infraestrutura necessária para a realização do processo.

É possível observar nessas experiências de orçamento participativo e nos diferentes posicionamentos em relação ao processo que o OP apresenta resultados nem sempre satisfatórios, aquém do que se espera de uma democracia participativa ou deliberativa, embora sejam ressaltados aspectos positivos desse mecanismo para a democracia brasileira. Essa questão pode ser mais bem entendida por meio da análise de um caso específico, a exemplo do OPVC, que veremos a seguir como se operacionaliza, como este se situa entre as fronteiras da democracia representativa e da democracia participativa, e se efetivamente democratiza a gestão municipal.

\section{O Orçamento Participativo de Vitória da Conquista (BA)}

O município de Vitória da Conquista situa-se na região Centro-sul da Bahia, a $503 \mathrm{~km}$ de Salvador. Sua população, em 2010, foi calculada em 306.866 habitantes (IBGE, 2011a). Para 
2011, sua população foi estimada em 310.129 habitantes (SEI, 2011b), mantendo sua posição de terceira cidade em tamanho populacional no estado. Seu PIB per capita evoluiu expressivamente de R\$3.678,00, em 2004, para R\$ 8.346,46 em 2008 (IBGE, 2011b). Segundo informações da Superintendência de Estudos Econômicos e Sociais da Bahia (SEI, 2011a), em 2006 o município estava em 15 lugar no Índice de Desenvolvimento Econômico, em comparação com os demais municípios do estado; todavia, seu Índice de Desenvolvimento Social era o quarto melhor do estado, assim como seu Índice do Nível de Saúde (4o lugar) e seu Índice do Produto Municipal (7o lugar). Por outro lado, o município encontrava-se mal posicionado no ranking estadual em índices como: Infraestrutura (42 lugar), Nível de Educação (32ำ lugar), Qualificação de Mão de Obra (22ํ lugar) e de Serviços Básicos (19ํlugar).

Entre 2007 e 2008 o município de Vitória da Conquista estava entre os cinco maiores do estado da Bahia em termos do Valor Agregado de Serviços (SEI, 2008), com participação de 2,78\% no total do estado (5o lugar). Tal participação era de 2,04\%, em 1999; de 2,70\%, em 2006; e de 2,80\%, em 2007 (SEI, 2007). A equipe da SEI avaliou do seguinte modo a situação do município:

O município de Vitória da Conquista (2,78\%), com uma população bastante expressiva, a 3 a maior da Bahia, aparece no ranking pelas suas atividades comerciais, assim como pela prestação de serviços às famílias e às empresas. Um comércio forte e muito dinâmico coloca a cidade entre os cem maiores centros comerciais do país. Esse pujante comércio abrange toda a região Sudoeste do estado. Vitória da Conquista também se destaca por possuir um setor educacional privilegiado formado por excelentes escolas além de contar com faculdades e universidades. (SEI, 2008:5)

A experiência do orçamento participativo em Vitória da Conquista inicia-se em 1997, após a eleição e posse de prefeito do Partido dos Trabalhadores (PT) para a gestão 1997-2000. A nova administração encontrou o município com uma série de dificuldades financeiras e administrativas, tais como o elevado endividamento, o atraso no pagamento de salários, décimo terceiro salário e encargos sociais dos servidores municipais, a falta de crédito junto aos fornecedores de bens e serviços (em razão de atrasos nos pagamentos) e a paralisação de serviços essenciais, a exemplo da coleta de lixo. Estima-se que a dívida pública existente, segundo informações da Prefeitura, era de R 80 milhões, para um orçamento público de cerca de R $\$$ 30 milhões/ano. ${ }^{2}$ Essa realidade foi discutida e pesquisada em alguns estudos, a exemplo de Andrade (2005), Craveiro e Lima (2003), Pinho (2006) e Wampler e Barboza (2000).

A gestão municipal enfrentava outro desafio, de caráter político, que era uma acirrada oposição na Câmara de Vereadores, com maioria oposicionista, além da oposição do governo federal e até a hostilidade por parte do governo estadual liderado pelo Partido da Frente Liberal (PFL, controlado pelo então senador Antônio Carlos Magalhães), que chegou a vetar

\footnotetext{
${ }^{2}$ Informação obtida em entrevista com secretário municipal da PMVC, em 6 de agosto de 2010.
} 
diversos projetos encaminhados pelo Executivo Municipal, a exemplo de aterro sanitário, municipalização da saúde e da gestão do trânsito e o Programa de Eficientização da Iluminação Pública (Procel), como se constata em Pinho (2006). Como vimos aqui, a cerrada oposição do governo carlista também provocou um verdadeiro cerco político à gestão da prefeita de Salvador, no período de 1993-96, dificultando a gestão daquele município.

Diante de tal realidade, a Prefeitura de Vitória da Conquista convocou a população para discutir a situação financeira e administrativa do município e mesmo para colaborar na solução de alguns problemas mais graves e imediatos, como a situação da coleta de lixo, que necessitou do apoio de empresários e da população para ser retomada. Iniciou-se assim um processo que pode ser relacionado com a democracia participativa, no qual a Prefeitura demonstrou transparência em relação à sua situação financeira e convocou a população para ajudar na busca de soluções.

Ainda no ano de 1997 foi criado o Orçamento Participativo, com a realização de 22 plenárias populares nas zonas urbana e rural, participando 1.345 pessoas, que elegeram 86 delegados para o I Congresso do Orçamento Participativo (PMVC, 2009). Temos aqui uma característica do OP-VC, e que pode ser associada com a tradição de mobilização herdada dos movimentos sociais pelos novos fóruns participativos, como se nota em Avrtizer (2009a), que é a realização de congressos, o que não se observa em outras experiências no Brasil.

Outra peculiaridade do I Congresso do OP-VC foi a sua realização em meio a uma conjuntura de crise política e administrativa da Prefeitura, de elevado endividamento, sendo a capacidade de investimento público praticamente nula. Esse fato contraria o que se observa em outros processos de OP, nos quais o principal objetivo é a discussão do investimento público, a definição de suas prioridades e a aprovação de obras públicas (Avritzer, 2003, 2009a; Fedozzi, 1997; Genro e Souza, 1997; Marquetti, 2003; Navarro, 2003; Santos, 2009a, 2009b; Wampler, 2003).

No caso de Vitória da Conquista, o objetivo da gestão municipal era apresentar a situação de crise financeira e administrativa para a população e discutir conjuntamente as medidas que poderiam ser tomadas. Esse fato pode ser entendido de duas maneiras: por um lado, é possível dizer que havia um comprometimento dos gestores municipais com a participação da população, uma concepção próxima à ideia de democracia participativa, que admitia a participação como um meio para encontrar soluções para os problemas administrativos e políticos existentes. Por outro lado, a Prefeitura necessitava do apoio da população para que pudesse realizar seus objetivos, em meio à ausência de recursos para investimentos, manutenção da máquina pública e pagamento da dívida, além do isolamento político provocado pela forte oposição na Câmara Municipal e nos governos estadual e federal. Assim, existiria também uma razão estratégica para a proposição de um orçamento participativo, que pode ser visto como um meio de obtenção de apoio ao projeto político à frente da Prefeitura e para a implantação das medidas saneadoras requeridas.

O I Congresso do OP (1997) deliberou apenas sobre diretrizes para a gestão municipal, como "melhoria da arrecadação, celebração de convênios, contenção de despesas, priorizar a educação, saneamento, saúde, infraestrutura, emprego e renda” (PMVC, 2009:23). Suas re- 
soluções referem-se à implantação de uma política tributária progressiva, à reformulação do sistema municipal de arrecadação, à cobrança dos grandes débitos inscritos na Dívida Ativa, à prioridade a serviços e obras sociais em detrimento de "grandes obras", ao pagamento de salários e encargos atrasados, ao não pagamento de dívidas consideradas ilegítimas, à busca da adimplência da Prefeitura para torná-la apta aos programas e financiamentos institucionais (PMVC, 2009:44).

Na concepção de Avritzer (2003), para que o orçamento participativo possa influir sobre o "aprofundamento da democracia" alguns elementos devem ser considerados, como o aumento da participação da população na decisão sobre a distribuição dos recursos orçamentários, o aumento do acesso a recursos públicos e direitos, além do aumento da capacidade de decidir e de determinar as regras do processo deliberativo, o que não aconteceu neste primeiro momento do OP-VC.

Todavia, um orçamento participativo necessita de investimentos para garantir seu sucesso e continuidade, como avaliam alguns dos autores aqui abordados (Avritzer, 2003; Boschi, 1999; Milani, 2007), ou seja, é necessário haver capacidade financeira do município para executar as suas deliberações. Nesta pesquisa sobre o OP-VC, em muitos momentos se observou a ausência dessa capacidade na gestão municipal, com implicações no desenvolvimento do referido processo. O II Congresso do OP, por exemplo, previsto para 1998, foi adiado pelo fato de ser um ano eleitoral e o secretário municipal ao qual estava vinculado o OP-VC ser candidato a deputado, por isso a Coordenação do OP afirma ter optado por adiá-lo para evitar uma conotação eleitoreira do processo. ${ }^{3}$ Entretanto, com base na pesquisa documental, é possível afirmar que houve também uma razão estratégica para o adiamento, ou seja, a inexistência de recursos para investimentos em 1998, o que poderia causar maior desgaste ao processo.

A realização do II Congresso do OP-VC, em 1999, contou com maior participação da população, com 2.883 participantes, em 45 plenárias, tendo sido eleitos 194 delegados (PMVC, 2009:passim). Pela primeira vez os delegados eleitos puderam deliberar sobre investimentos públicos, uma vez que a Prefeitura Municipal disponibilizou R\$ 1 milhão do seu orçamento, o que correspondia a menos de $2 \%$ do orçamento total do município (Andrade, 2005:113). Os delegados aprovaram 32 obras, destinadas às zonas urbana e rural, com predomínio de obras de pavimentação, construção e ampliação de escolas, construção de poços artesianos e iluminação pública (PMVC, 2009:121-124). O montante liberado era muito aquém dos valores das obras solicitadas nas plenárias populares, o que gerou muitas discussões sobre quais obras seriam aprovadas e foi motivo de insatisfação de parte dos participantes, o que pode ser constatado na pesquisa às Atas de Plenárias, de Fóruns de Delegados e dos Congressos.

A baixa capacidade de investimentos da Prefeitura Municipal era um empecilho para a manutenção de uma política de participação social, o que poderia comprometer todo o processo e impedir os planos para uma futura reeleição do prefeito. Uma solução encontra-

\footnotetext{
${ }^{3}$ Informação obtida em entrevista com secretário municipal da PMVC, em 6 de agosto de 2010.
} 
da pelos gestores foi aproveitar a conjuntura favorável criada com a renegociação-padrão das dívidas municipais com o governo federal (1999-2000), que reduziu o passivo total dos municípios endividados e facilitou a recuperação da capacidade financeira e recorrer às possibilidades externas de financiamento, especialmente àquelas ligadas à saúde e à educação, em que se concentrava boa parte das demandas do OP-VC. Assegurados os recursos do Fundo de Manutenção e Desenvolvimento do Ensino Fundamental e de Valorização do Magistério (Fundef), após o exercício de 1998, restava à administração municipal lutar pela municipalização da saúde, que enfrentava a oposição da Câmara de Vereadores e do governo estadual. Novamente recorreu-se à estratégia da participação social, com a mobilização da população em prol da municipalização da saúde, aprovada, após muita disputa política, na IV Conferência Municipal de Saúde de Vitória da Conquista, realizada em 1999.

A administração municipal de Vitória da Conquista deu continuidade ao processo de participação social junto à gestão por meio do OP, da criação de conselhos gestores, da realização de conferências públicas e das audiências do Plano Diretor. Essa ampliação da participação se refletiu no III Congresso do OP-VC, realizado em 2000, quando participaram 3.283 pessoas, nas 48 plenárias populares, que elegeram 225 delegados (PMVC, 2009:115119). Andrade (2005:121) calculou em 13,87\% o crescimento da participação no OP-VC entre 1999 e 2000.

A ampliação da participação social por meio da criação de outras instâncias se aproxima do que Boaventura Santos (2009b) qualifica como "aprofundamento da cultura participativa", isto é, a criação de outras formas de participação, como o aumento do número de conselhos, a partir dos resultados observados com a realização do orçamento participativo. Ainda em 2000 foram criadas as "Caravanas da Cidadania", similares às "Caravanas de Prioridades" (do OP-BH), com as visitas de delegados às obras indicadas "(...) para decidirem na aplicação dos recursos com mais consciência" (PMVC, 2009:89).

O III Congresso (2000) do OP-VC aprovou 36 obras, com o custo estimado em R\$ 994.200,00, mas o custo real orçado foi de R\$1.862.342,00 (PMVC, 2009:119-121). Ainda assim, o valor aprovado para as obras era muito inferior ao valor total das demandas apresentadas nas plenárias rurais e urbanas. A insuficiência de recursos para investimentos foi uma das características do processo de OP em Vitória da Conquista, o que de certa forma comprometeu sua credibilidade e dificultou uma maior participação da população. Em 2001, por exemplo, a realização do Congresso foi adiada mais uma vez, tendo sido realizado apenas um Encontro de Delegados, o que foi visto como um prejuízo ao processo, uma quebra de continuidade, "(...) aumentando as críticas, cobranças e insatisfações da população" (Andrade, 2005:123).

A variável capacidade administrativa e financeira é essencial a um modelo de análise do OP comum na pesquisa acadêmica brasileira (Avritzer, 2003; Marquetti, 2003) e em parte explica a limitada participação da sociedade civil no OP-VC. Andrade (2005:129) calculou a taxa de participação no OP-VC sobre a população total em 0,51\% (1997), 1\% (1999), 1,25\% (2000) e 1,81\% (2002). A presente pesquisa concluiu que a participação no OP-VC, em relação à população total do município, representava aproximadamente 1,15\% da população 
em 2008 e, em 2011, essa taxa estava em torno de 1,21\%, similar à margem de participação constatada por Andrade (2005) para o período de 1997-2002. Esse índice de participação da sociedade civil é relativamente menor do que aquele observado por Avritzer (2003) para o OP de Porto Alegre, que girava em torno de $2 \%$ da população, com números absolutos muito maiores e apresentando um histórico de participação e mobilização política mais consistente do que o município de Vitória da Conquista. De todo modo, Milani (2008), ao analisar experiências de participação social na América Latina e na Europa, observa que em todas essas experiências os números da participação são "bastante modestos" quando comparados com a população total da cidade em que ocorrem, mesmo porque: “(...) os municípios não vivem em permanente estado de euforia associativa e participativa” (Milani, 2008:566).

Em relação à participação da população, a pesquisa realizada em 2011, com os delegados do IX Congresso do OP-VC, ${ }^{4}$ revelou que 55,7\% deles apresentavam renda familiar mensal de até um salário-mínimo, que havia um equilíbrio entre a participação masculina $(47,7 \%)$ e feminina $(42,7 \%)^{5}$ e que $69,5 \%$ dos delegados estavam entre 21 e 50 anos. Quanto à origem dos delegados, 53,8\% viviam na zona rural e 42,4\% viviam na zona urbana. Dos delegados que responderam ao questionário, $11,8 \%$ apenas leem e escrevem e 13,4\% possuem ensino elementar incompleto. No quesito ocupação principal dos delegados destacavam-se trabalhadores rurais ou agricultores (19,6\%), donas de casa $(14,3 \%)$, agentes comunitários de saúde $(13,1 \%)$, servidores públicos $(7,7 \%)$ e aposentados $(6,5 \%)$.

Outra importante constatação da pesquisa de campo foi o expressivo associativismo dos delegados do OP-VC, com 51,5\% deles afirmando pertencer a alguma associação (contra $32,4 \%$ de não filiados). Já o percentual de sindicalizados foi de $27,1 \%$, especialmente entre os trabalhadores rurais, mas o percentual de filiação partidária dos delegados era de 34,7\%, muito superior ao percentual de filiados a partidos políticos entre o total da população brasileira (cerca de 7,2\%, em 2011), conforme dados pesquisados junto ao Tribunal Superior Eleitoral (TSE). Dentre os partidos políticos aos quais os delegados informaram ser filiados, o Partido dos Trabalhadores (PT) liderava com 77,9\% das indicações; não por acaso, é o partido que lidera a coligação que dirige a Prefeitura Municipal desde 1997, seguido de outro partido da mesma coligação, o Partido Socialista Brasileiro (PSB), com 9,1\% das filiações.

A pesquisa revelou que o orçamento participativo possibilitou a ampliação da base política da coligação que governa o município desde 1997 e contribuiu para a formação de laços políticos entre os participantes do OP e a gestão municipal que podem ter contribuído no processo de constante reeleição dos candidatos da coligação governista em quatro disputas eleitorais sucessivas. A vinculação partidária dos participantes do OP em muitos municípios desperta a atenção de vários pesquisadores, embora aqui não seja possível aprofundar essa discussão, que pode ser iniciada em autores como Bello (2007), Navarro (2003) e Romão (2010).

\footnotetext{
${ }^{4}$ Foram aplicados questionários a 350 delegados do IX Congresso do OP-VC (28.5.2011), escolhidos de modo não probabilístico, como amostra por conveniência ou acidental (Barros e Lehfeld, 1990), dentre os seus 530 delegados eleitos, dos quais 263 questionários foram respondidos e devolvidos ao pesquisador (75\%) e 262 foram considerados válidos.

${ }^{5}$ 9,6\% dos delegados que responderam aos questionários não informaram o gênero.
} 
Embora com o quadro de dificuldades, a PMVC prosseguiu sua política participativa realizando o IV Congresso do OP, em 2002. O que pode demonstrar um acerto da estratégia de adiamento do Congresso em 2001 (dada a falta de recursos para investimentos) foi o aumento da participação popular para 4.768 pessoas, em 31 plenárias, elegendo 476 delegados (PMVC, 2009:163), o que aparentemente indica a existência de credibilidade na política participativa em uma parcela da população. Embora houvesse uma nova metodologia que discutia todo o orçamento municipal, estimado em R 124 milhões para 2003, somente foram aprovados R\$ 1.600.000,00, para investimento em 53 obras (Andrade, 2005:125; PMVC, 2009:208210). Esse reduzido percentual de investimentos de $1,29 \%$ do orçamento total repercutiu em críticas e cobranças nas plenárias de 2003 quanto às obras aprovadas desde o I Congresso e não realizadas até então, com reflexos na redução da participação no V Congresso, em 2003 (2.397 pessoas).

A partir do VI Congresso (2004) houve uma importante mudança metodológica no OP-VC: deixou-se de discutir valores prefixados para os investimentos e passou-se a discutir por "eixos" e por demandas apresentadas, sendo definidos oito eixos em 2004 (PMVC, 2009:372-393). Assim, os delegados não definiam mais a parcela do orçamento que deveria ser investida, apenas as demandas prioritárias. Essa mudança tem caráter estratégico. Diante da permanente dificuldade em atender às demandas aprovadas, com obras aprovadas arrastando-se por anos até a sua conclusão, os gestores municipais optaram por aprovar apenas eixos gerais de investimentos, demandas de caráter geral, que normalmente constariam de um programa de governo, mas de difícil definição das obras específicas e, por consequência, de difícil cobrança por parte da população e pelos delegados do OP. Além disso, um maior número de demandas podia ser aprovado, contemplando um maior número de comunidades ou bairros, o que atende ao aspecto político-eleitoral, embora não ficassem claros à população as possibilidades e os prazos de seu efetivo atendimento.

Com essa nova metodologia, a Prefeitura Municipal realizava as obras públicas de acordo com a sua disponibilidade de recursos para investimentos, inclusive contando com recursos captados junto a fontes externas (programas federais e estaduais) ou de emendas parlamentares aprovadas junto ao Orçamento da União, e as obras aprovadas nos congressos do OP-VC eram incluídas dentre as obras realizadas pela prefeitura, junto àquelas não discutidas no fórum do orçamento.

É evidente que essa estratégia também apresenta riscos. Em levantamento da Gerência de Mobilização Social e OP, em 2010, para ser encaminhado ao prefeito, referente às demandas aprovadas pelo VIII Congresso do OP-VC (2008), observa-se que, de 31 demandas referentes à pavimentação, apenas seis foram atendidas; as solicitações de extensão de rede elétrica, de urbanização de praças e jardins, de sistemas de tratamento de água, assim como várias demandas da educação, estavam apenas parcialmente atendidas. A demanda para a construção de 23 creches nas zonas rural e urbana não tinha nenhuma creche construída ou em construção (PMVC, 2010).

Com base nos aspectos aqui apresentados, é possível identificar algumas falhas no processo de orçamento participativo desenvolvido em Vitória da Conquista, como a falta de 
capacidade para implantar parte significativa de suas deliberações, indicando ausência da chamada "efetividade deliberativa", ou seja, da capacidade efetiva de influenciar, controlar, decidir sobre as políticas públicas, institucionalizando procedimentos, produzindo resultados dos debates relacionados com a deliberação pública para implantar suas decisões (Cunha, 2007). Os problemas financeiros enfrentados pela gestão municipal desde a implantação do orçamento participativo, os atrasos na execução e conclusão de obras aprovadas geraram grande frustração na população e levaram ao descrédito no OP-VC.

A mudança da metodologia para a discussão por eixos, a partir de 2004, também não trouxe avanços ao processo porque gerou expectativas de atendimento das reivindicações apresentadas nas plenárias, mas sem definição de uma prioridade de execução e sem uma avaliação criteriosa das demandas que deveriam constar do OP. Também se nota a ausência de critérios técnicos para a definição de prioridades entre os bairros e comunidades, como se observa, por exemplo, nos OPs de Porto Alegre e Belo Horizonte (Avritzer, 2009a; Fedozzi, 1997; Santos, 2009b).

Finalmente, uma grande contradição e debilidade que se observa no OP de Vitória da Conquista é a discussão de um orçamento municipal, a aprovação de demandas para esse orçamento, sem maior definição sobre os valores financeiros envolvidos, sobre a capacidade da Prefeitura em realizar as obras, sobre as demandas pendentes e quanto custaria atendê-las, o que pode, inclusive, explicar em parte o não atendimento de muitas demandas aprovadas.

\section{Considerações finais}

O presente artigo sobre o Orçamento Participativo de Vitória da Conquista (BA) buscou analisar suas possibilidades efetivas em democratizar a gestão pública municipal e a distribuição dos seus recursos orçamentários. A maioria dos autores cotejados neste estudo caracteriza o OP como um caso de democracia participativa ou de combinação entre esta e a democracia representativa, pois realiza plenárias populares ao lado da eleição de representantes para conselhos e congressos. Essa combinação entre dois modelos de democracia foi vista como arranjos de "coexistência" e de "complementaridade" (Santos e Avritzer, 2009) e ajudou a entender o objeto deste estudo.

Observou-se, em Vitória da Conquista, que o Governo Participativo foi levado a desenvolver uma estratégia política para a obtenção do apoio necessário para enfrentar o grave quadro da gestão municipal, que envolvia a defesa de propostas de gestão que se aproximavam de uma democracia participativa, como a criação do orçamento participativo e depois dos conselhos gestores, conferências de políticas públicas, Conferência da Cidade, Agenda 21, novo Plano Diretor Urbano e outras.

Ao tempo em que ampliava os fóruns participativos, a gestão municipal enfrentava dificuldades para fazer com que o OP-VC funcionasse efetivamente, principalmente devido à falta de recursos para atender às demandas aprovadas em seus congressos e plenárias, outras dificuldades administrativas e políticas, e até mesmo a falta de prioridade às deliberações do 
OP, no momento da recuperação de parte da capacidade financeira do município. Tais fatos levaram a adiamentos dos congressos do OP, a atrasos na realização de obras aprovadas e a mudanças em sua metodologia ou "desenho institucional", com desgastes na credibilidade do processo e limitação da participação no OP-VC a algo em torno de 1,2\% da população, em especial de filiados e simpatizantes dos partidos da base aliada.

Considerando a evolução do OP-VC, suas dificuldades e reveses, o caráter da participação popular nas suas plenárias, fóruns e congressos, é possível afirmar que o orçamento participativo em Vitória da Conquista contribui apenas parcialmente com a democratização da gestão pública municipal, pois não consistiu em instrumento de efetiva participação da população na definição das políticas públicas e na aplicação dos recursos públicos. O OP-VC não atingiu, ao longo dos seus 16 anos, uma ampla participação entre os diferentes segmentos da sociedade civil, não foi capaz de realizar regularmente seus congressos anuais e nem garantiu o atendimento das demandas populares aprovadas em seus fóruns, gerando insatisfação, frustração e descrédito junto a alguns segmentos da população, especialmente em algumas áreas urbanas.

A análise evidencia que o orçamento participativo de Vitória da Conquista (BA) não apresenta "efetividade deliberativa" ou capacidade adequada para definir as prioridades específicas de cada comunidade ou bairro, aprová-las em seus congressos e exigir da administração municipal sua execução. A pesquisa documental não encontrou indícios de que o OP-VC apresente impacto significativo na situação financeira do município; ao contrário, esta impediu, em muitos momentos, a execução de suas deliberações. Também não foi constatado que o OP-VC fosse capaz de definir novas regras sobre as decisões dos gestores públicos relativas à distribuição dos recursos orçamentários; em alguns casos esses gestores ignoraram decisões do OP, em outros casos foram tomadas decisões prejudiciais ao próprio processo, como o adiamento de congressos e a não realização de obras aprovadas. Outro aspecto que contraria especialmente as proposições de Wampler (2003) refere-se à ausência de resultados claros do OP-VC para o público participante, que não vê os resultados daquilo que deliberou ou espera anos para a realização das obras.

Por fim, a pesquisa demonstrou que o OP-VC apresenta inúmeras falhas em sua realização, como a definição clara das prioridades, dos custos envolvidos para atendê-las, do tempo necessário para a execução, quanto à capacidade de fiscalizar a implementação das suas deliberações e à pouca aprendizagem institucional ao longo do processo, além de evidências da falta de prioridade a algumas demandas aprovadas, o que permite dizer que não há uma clara relação entre a realização do orçamento participativo em Vitória da Conquista e a melhoria da administração local, uma vez que é limitada a sua capacidade de "aprofundamento da democracia”, como preconiza Avritzer (2003). Essas conclusões indicam que a experiência participativa deve ser considerada em suas especificidades, uma vez que os pressupostos da democracia participativa nem sempre são inteiramente verificados em cada realidade concreta, sendo necessário buscar elementos que contribuam com seu entendimento e que possibilitem avaliar outras experiências semelhantes. 


\section{Referências}

ANDRADE, Juliana M. S. Participação popular, orçamento participativo e inversão de prioridades: a experiência de Vitória da Conquista — Bahia (1997-2002). Dissertação (mestrado em administração) — Universidade Salvador, Salvador, 2005.

AVRITZER, Leonardo. Modelos de deliberação democrática: uma análise do orçamento participativo no Brasil. In: SANTOS, Boaventura de S. (Org.). Democratizar a democracia: os caminhos da democracia participativa. Rio de Janeiro: Civilização Brasileira, 2009a. p. 561-597.

AVRITZER, Leonardo. O Orçamento Participativo e a teoria democrática: um balanço crítico. In: AVRITZER, Leonardo; NAVARRO, Zander (Org.). A inovação democrática no Brasil: o orçamento participativo. São Paulo: Cortez, 2003. p. 13-60.

AVRITZER, Leonardo. Participatory institutions in democratic Brazil. Baltimore: The Johns Hopkins University Press, 2009b.

AVRITZER, Leonardo; NAVARRO, Zander (Org.). A inovação democrática no Brasil: o orçamento participativo. São Paulo: Cortez, 2003.

BARROS, Aidil de J. P; LEHFELD, Neide A. de S. Projeto de pesquisa: propostas metodológicas. Petrópolis, RJ: Vozes, 1990.

BELLO, Carlos A. Orçamento participativo em São Paulo: uma invenção de limitado alcance. In: OLIVEIRA, Francisco de; RIZEK, Cibele S. (Org.). A era da indeterminação. São Paulo: Boitempo, 2007. p. 103-127.

BOSCHI, Renato R. Descentralização, clientelismo e capital social na governança urbana: comparando Belo Horizonte e Salvador. Dados, Rio de Janeiro, v. 42, n. 4, p. 655-690, 1999. Dis-

ponível em: <http://scielo.br/scielo.php?script=sci_arttext\&pid=S0011-525819990004000 02\&1ng =en\&nrm=iso > . Acesso em: 20 abr. 2012 .

BOSSOIS, Irene L. A formulação democrática do orçamento municipal: a experiência de Vila Velha-ES no período de 1983-1986. Revista de Administração Municipal, v. 34, n. 184, p. 6-11, jul./set. 1987.

COELHO, Vera S. P.; NOBRE, Marcos (Org.). Participação e deliberação: teoria democrática e experiências institucionais no Brasil contemporâneo. São Paulo: Ed. 34, 2004.

COÊLHO, Denílson B. Gestão municipal e arranjos participativos em Pernambuco. Entre racionalidade política e ajustes deliberativos. In: AVRITZER, Leonardo (Org.). A participação social no Nordeste. Belo Horizonte: Editora UFMG, 2007. p. 85-108.

COOPER, Donald R.; SCHINDLER, Pamela S. Métodos de pesquisa em administração. Porto Alegre: Bookman, 2003.

CRAVEIRO, Sílvia da S.; LIMA, Fernanda T. Tributação e política fiscal no nível municipal — um estudo de caso: o programa de fortalecimento financeiro do município de Vitória da Conquista/BA. In: ENCONTRO NACIONAL DA PÓS-GRADUAÇÃO EM ADMINISTRAÇÃO, XXVII, 2003, Atibaia, SP. Anais... São Paulo: Anpad, 20 a 24/9/2003. CD-ROM. 
CUNHA, Eleonora S. M. A efetividade deliberativa dos Conselhos Municipais de Saúde e de Criança e Adolescente no Nordeste. In: AVRITZER, Leonardo (Org.). A participação social no Nordeste. Belo Horizonte: Editora UFMG, 2007. p. 135-161.

DAHL, Robert A. Análise política moderna. Brasília: Editora Universidade de Brasília, 1981.

DAHL, Robert A. On political equality. New Haven: Yale University Press, 2006.

FEDOZZI, Luciano. Orçamento Participativo: reflexões sobre a experiência de Porto Alegre. Porto Alegre: Tomo Editorial; Rio de Janeiro: Fase, 1997.

FERNANDES, Antônio S. A. Gestão municipal e participação social no Brasil: a trajetória de Recife e Salvador (1986-2000). São Paulo: Annablume; Fapesp, 2004.

FLICK, Uwe. Qualidade na pesquisa qualitativa. Porto Alegre: Artmed, 2009.

FUNDAÇÃO INSTITUTO BRASILEIRO DE GEOGRAFIA E ESTATÍSTICA — IBGE. Cidades@.Bahia, Vitória da Conquista, população 2010. 2011a. Disponível em: <www. ibge.gov.br/cidadesat/link. php? codmun $=293330>$. Acesso em: 5 out. 2011.

FUNDAÇÃO INSTITUTO BRASILEIRO DE GEOGRAFIA E ESTATÍSTICA — IBGE Cidades@. Bahia, Vitória da Conquista, Produto Interno Bruto dos municípios. 2011b. Disponível em: <www.ibge.gov. br/cidadesat/link.php?codmun $=293330>$. Acesso em: 5 out. 2011.

GENRO, Tarso; SOUZA, Ubiratan de. Orçamento Participativo: a experiência de Porto Alegre. São Paulo: Fundação Perseu Abramo, 1997.

GOMES, Maria A. Orçamento Participativo de Belo Horizonte: um instrumento de planejamento da gestão democrática. In: AZEVEDO, Sérgio de; FERNANDES, Rodrigo B. (Org.). Orçamento Participativo: construindo a democracia. Rio de Janeiro: Revan, 2005. p. 49-65.

HELD, David. Modelos de democracia. Madri: Alianza Editorial, 2007.

KLIKSBERG, Bernardo. ¿Cómo avanzar la participación en el continente más desigual de todos? Rev. Adm. Pública, v. 41, n. 3, p. 537-581, maio/jun. 2007. Disponível em: < http://bibliotecadigital.fgv. br/ojs/index.php/rap/article/view/6598/5182>. Acesso em: 2 jul. 2013.

MARQUETTI, Adalmir. Participação e redistribuição: o orçamento participativo em Porto Alegre. In: AVRITZER, Leonardo; NAVARRO, Zander (Org.). A inovação democrática no Brasil: o orçamento participativo. São Paulo: Cortez, 2003. p. 129-156.

MILANI, Carlos R. S. O princípio da participação social na gestão de políticas públicas locais: uma análise de experiências latino-americanas e europeias. Rev. Adm. Pública, v. 42, n. 3, p. 551-579, maio/jun. 2008. Disponível em: <http://bibliotecadigital. fgv.br/ojs/index.php/rap/ article/ view/6645/5229>. Acesso em: 8 out. 2012.

MILANI, Carlos R. S. Participação social e ação pública local na Bahia. In: AVRITZER, Leonardo (Org.). A participação social no Nordeste. Belo Horizonte: Editora UFMG, 2007. p. 215-235.

MOTA, Áurea. Fissuras na estrutura do mandonismo. Transformações recentes e ampliação do escopo democrático na Bahia. In: AVRITZER, Leonardo (Org.). A participação social no Nordeste. Belo Horizonte: Editora UFMG, 2007. p. 45-63. 
NAVARRO, Zander. O “Orçamento Participativo" de Porto Alegre (1989-2002): um conciso comentário crítico. In: AVRITZER, Leonardo; NAVARRO, Zander (Org.). A inovação democrática no Brasil: o orçamento participativo. São Paulo: Cortez, 2003. p. 89-128.

PATEMAN, Carole. Participation and democratic theory. Nova York: Cambridge University Press, 1970.

PINHO, José A. G. de. Inovação em contexto de múltiplas adversidades: o caso de Vitória da Conquista, Bahia. In: JACOBI, Pedro; PINHO, José A. G. de (Org.). Inovação no campo da gestão pública local: novos desafios, novos patamares. Rio de Janeiro: Editora FGV, 2006. p. 185-204.

PIRES, Roberto; TOMAS, Maria C. Instituições participativas e gestão municipal no Nordeste. Uma análise dos efeitos da participação sobre as práticas de governo. In: AVRITZER, Leonardo (Org.). A participação social no Nordeste. Belo Horizonte: Editora UFMG, 2007. p. 163-189.

PIRES, Valdemir. A participação da sociedade nos processos orçamentários: a experiência brasileira recente. Monografia (IV Prêmio Tesouro Nacional) — Ministério da Fazenda, Brasília, 2000. Disponível em: <www.unimep.br/fgn/economia/pires.html>. Acesso em: 5 mar. 2014.

PIRES, Valdemir. Orçamento Participativo: o que é, para que serve, como se faz. Barueri, SP: Manole, 2001.

PREFEITURA MUNICIPAL DE VITÓRIA DA CONQUISTA-BA (PMVC). Gerência de Mobilização Social e Orçamento Participativo. A história do Orçamento Participativo em Vitória da Conquista, 1997-2009. 2009. Arquivo digital no formato Word for Windows (.doc).

PREFEITURA MUNICIPAL DE VITÓRIA DA CONQUISTA-BA (PMVC). Secretaria de Governo. Coordenação do Orçamento Participativo. Propostas dos grupos por eixos. Demandas aprovadas no VIII Congresso do OP (2008). 2010. Mimeografado.

ROCHA, Alexssandro C. Alcances do orçamento participativo nos investimentos educacionais realizados pela Prefeitura Municipal de Vitória da Conquista no período de 2002 a 2007. Dissertação (mestrado) — Faculdade de Educação, Universidade Federal da Bahia, Salvador, 2008.

ROMÃO, Wagner de M. Nas franjas da sociedade política: estudo sobre o orçamento participativo. Tese (doutorado) — Faculdade de Filosofia, Letras e Ciências Humanas, Universidade de São Paulo, São Paulo, 2010.

RUIZ SÁNCHEZ, Félix. Orçamento Participativo: teoria e prática. São Paulo: Cortez, 2002.

SANTOS, Boaventura de S. (Org.). Democratizar a democracia: os caminhos da democracia participativa. Rio de Janeiro: Civilização Brasileira, 2009a.

SANTOS, Boaventura de S. Orçamento participativo em Porto Alegre: para uma democracia redistributiva. In: SANTOS, Boaventura de S. (Org.). Democratizar a democracia: os caminhos da democracia participativa. Rio de Janeiro: Civilização Brasileira, 2009b. p. 455-559.

SANTOS, Boaventura de S.; AVRITZER, Leonardo. Introdução: para ampliar o cânone democrático. In: SANTOS, Boaventura de S. (Org.). Democratizar a democracia: os caminhos da democracia participativa. Rio de Janeiro: Civilização Brasileira, 2009. p. 39-82. 
SARTORI. Giovanni. A teoria da democracia revisitada. O debate contemporâneo. São Paulo: Ática, 1994. v. 1.

SUPERINTENDÊNCIA DE ESTUDOS ECONÔMICOS E SOCIAIS DA BAHIA — SEI. Boletim Técnico 2007. Resultado do PIB municipal revela leve desconcentração espacial na economia baiana. Disponível em: $<$ www.sei.ba.gov.br/index.php? option $=$ com_content $\&$ view $=$ article\&id $=539 \&$ Itemid $=88>$. Acesso em: 5 out. 2011.

SUPERINTENDÊNCIA DE ESTUDOS ECONÔMICOS E SOCIAIS DA BAHIA — SEI. Boletim Técnico 2008. PIB municipal revela maior dinâmica dos municípios agroindustriais em 2008. Disponível em: $<$ www.sei.ba.gov.br/index.php?option $=$ com_ content\&view $=$ article\&id $=539 \&$ Itemid $=88>$. Acesso em: 5 out. 2011.

SUPERINTENDÊNCIA DE ESTUDOS ECONÔMICOS E SOCIAIS DA BAHIA — SEI. Municípios em síntese. Mapa municípios em síntese, economia. Tabela: Índices por Município e ano com ranking, 2006. Município de Vitória da Conquista. 2011a. Disponível em: <www. sei.ba.gov.br/munsintese/ index.wsp?tmp.cbmun.mun=2933307>. Acesso em: 5 out. 2011.

SUPERINTENDÊNCIA DE ESTUDOS ECONÔMICOS E SOCIAIS DA BAHIA — SEI. SIDE — Sistema de Dados Estatísticos. Consulta ao banco de dados. População Estimada, ano 2011. 2011b. Disponível em: <www.sei.ba.gov.br/side/frame_tabela.wsp ?tmp. volta $=* \&$ tmp. tabela $=$ t103>. Acesso em: 5 out. 2011.

WAMPLER, Brian. Orçamento Participativo: uma explicação para as amplas variações nos resultados. In: AVRITZER, Leonardo; NAVARRO, Zander (Org.). A inovação democrática no Brasil: o orçamento participativo. São Paulo: Cortez, 2003. p. 61-86.

WAMPLER, Brian; BARBOZA, Hélio B. Fortalecimento financeiro do município com justiça fiscal a serviço da cidadania. In: FARAH, Marta F. S.; BARBOZA, Hélio B. (Org.). Novas experiências de gestão pública e cidadania. Rio de Janeiro: FGV, 2000. p. 175-185.

YIN, Robert K. Estudo de caso: planejamento e métodos. Porto Alegre: Bookman, 2005.

Flávio Santos Novaes, graduado em administração (Uesb), onde trabalha como analista universitário. É mestre e doutorando em administração pelo Núcleo de Pós-Graduação em Administração (NPGA) da Universidade Federal da Bahia (Ufba). E-mail: flavaonovaes@yahoo.com.br.

Maria Elisabete Pereira dos Santos, bacharel em ciências sociais (Ufba), mestre em ciências sociais (Ufba) e doutora em ciências sociais (IFCH/Unicamp). Pesquisadora do Núcleo de Estudos sobre Poder e Organizações Locais — NepoL/Ciags-NPGA/Ufba, coordenadora do Grupo de Pesquisa sobre Águas — Grupo Águas/CNPq, é professora adjunta II da Escola de Administração da Ufba. E-mail: beteps@ufba.br. 